This item was submitted to Loughborough's Research Repository by the author.

Items in Figshare are protected by copyright, with all rights reserved, unless otherwise indicated.

\title{
Synthetic inertia control based on fuzzy adaptive differential evolution
}

PLEASE CITE THE PUBLISHED VERSION

https://doi.org/10.1016/j.ijepes.2018.09.009

PUBLISHER

(c) Elsevier

VERSION

AM (Accepted Manuscript)

PUBLISHER STATEMENT

This paper was accepted for publication in the journal International Journal of Electrical Power \& Energy Systems and the definitive published version is available at https://doi.org/10.1016/j.ijepes.2018.09.009.

\section{LICENCE}

CC BY-NC-ND 4.0

\section{REPOSITORY RECORD}

Chamorro, Harold R., Ivan Riano, Reinhard Gerndt, Ivan Zelinka, Francisco M. Gonzalez-Longatt, and Vijay K. Sood. 2019. "Synthetic Inertia Control Based on Fuzzy Adaptive Differential Evolution". figshare. https://hdl.handle.net/2134/35158. 


\title{
Synthetic Inertia Control based on Fuzzy Adaptive Differential Evolution
}

\author{
Harold R. Chamorro ${ }^{\mathrm{a}, 1}$, Ivan Riaño ${ }^{\mathrm{b}}$, Reinhard Gerndt ${ }^{\mathrm{b}}$, Ivan Zelinka ${ }^{\mathrm{c}}$, Francisco Gonzalez-Longatt ${ }^{\mathrm{d}}$, Vijay K. Sood ${ }^{\mathrm{e}}$ \\ ${ }^{a}$ Department of Electric Power Systems, KTH Royal Institute of Technology, Tekninkringen 33, 10044 Stockholm, Sweden \\ ${ }^{b}$ Ostfalia University of Applied Sciences, Wolfenbüttel, Germany \\ ${ }^{c}$ VSB Technical University of Ostrava, Ostrava, Czech Republic \\ ${ }^{d}$ Loughborough University, Leicestershire, United Kingdom \\ ${ }^{e}$ Department of Electrical and Computer Engineering of the University of Ontario, Institute of Technology, Ontario, Canada
}

\begin{abstract}
The transformation of the traditional transmission power systems due to the current rise of non-synchronous generation on it presents new engineering challenges. One of the challenges is the degradation of the inertial response due to the large penetration of high power converters used for the interconnection of renewables energy sources. The addition of a supplementary synthetic inertia control loop can contribute to the improvement of the inertial response. This paper proposes the application of a novel Fuzzy Adaptive Differential Evolution (FADE) algorithm for the tuning of a fuzzy controller for the improvement of the synthetic inertia control in power systems. The method is validated with two test power systems: (i) an aggregated power system and its purpose is to understand the controller-system behavior, and (ii) a two-area test power system where one of the synchronous machine has been replaced by a a full aggregated model of a Wind Turbine Generator (WTG), whereby different limits in the tuning process can be analyzed. Results demonstrate the evolution of the membership functions and the inertial response enhancement in the respective test cases. Moreover, the appropriate tuning of the controller shows that it is possible to substantially reduce the instantaneous frequency deviation.
\end{abstract}

Keywords: Synthetic Inertia, Differential Evolution, Fuzzy Logic Control, Frequency Response, Non-Synchronous Generation Integration

\section{Introduction}

To reduce the pollution and produce clean electricity, many countries' national environmental policies have targeted to achieve a large percentage integration of non-synchronous generation into the grid [1]. However, the challenge of integrating renewables into the overall power delivery has generated a common question: what is the impact of such integration on the power system stability [2]?. During the last decade, significant research studies and proposals have been addressed to that question by several Transmission System Operators (TSO) [3], manufacturers [4], research energy centres [5], and governmental associations around the world [6].

Since the transmission grid is the central artery that delivers power from generation plants to million of users, it is important to understand the impact of the large-scale integration of the non-synchronous generation on the power systems dynamics behaviour [7]. The development of the full scale converters has made possible the renewable energy sources interconnection as well as the High Voltage Direct Current (HVDC) transmission capability. The full converters have enhanced the power exchange over long distances achieving a high penetration level of renewables [8].

However, the large-scale integration of renewables creates different challenges such as the provision of an uninterrupted supply and the stability impact on the system. Different dynamic effects have been observed and studied based on the decoupling effect produced by the power electronic interface. The main phenomena studies regarding the stability are mainly the small signal stability [9], the transient stability [10], the coherency [11], and the frequency response

*corresponding author, E-mail address:hrcv@kth.se

Email address: hrcv@kth. se (Harold R. Chamorro) 
[12]. This latter aspect, is the requirement of maintaining the frequency stability within the respective boundaries of the system [13].

In order to maintain these limits, the frequency control should act in a manner such that the balance between generation and load is always met. The frequency response in power systems can be divided into different time frames:

- Initially, an inherent action named as inertial frequency response is present, which takes energy from the rotating masses to oppose a frequency deviation from the scheduled frequency [14].

- In the next stage, the automatic governing systems are activated to keep the frequency deviation to an acceptable level (primary control).

- Finally, the secondary control action is performed which restores the used reserves and the system frequency to its nominal value.

Non-synchronous generation (a non-inertial generation) is unable to contribute to the frequency response, unless an extra supplementary control - the so-called synthetic inertia [15], hidden [16] or virtual inertia [17] - is added. This supplementary control is able to contribute to the inertial response by injecting additional power obtained from dynamics of the wind power.

To overcome this problem, many control techniques have been adopted in the synthetic inertia control loop. The fixed (P/I/D) proportional/integral/derivative control combinations have been adopted in the synthetic inertia control loop [18]. By applying a slight change in the inverter electrical power set-point, the kinetic energy from the wind dynamics is released [19]. This control action reduces the frequency dip and the rate of change of frequency (RoCoF) [20]. Nevertheless, this extra power can only be extracted for up-to 10s [21].

In recent times, soft computing methods such as neural networks, fuzzy logic, genetic algorithm, and swarm intelligence controllers are replacing the conventional techniques [22], [23]. These techniques have been successfully applied to different power systems applications such as microgrids [24], Power System Stabilisers [25], HVDC [26], FACTSs [27], etc.

Fuzzy systems can be embedded in Hardware in the Loop (HIL) platforms in order to emulate real-time systems and understand the performance of the controllers with the respective plants [28]. A succesfull application of fuzzy systems in real systems environments is shown in [29], where the permanent magnet motor response is improved through fuzzy logic, in a micro wind system. Possible options to implement fuzzy inference systems in transmission level rely on the use of fully dedicated laboratories [30], [31], however this implementation is out of the scope of this paper.

Differential Evolution (DE) is a newer branch of evolutionary algorithms like Parallel Simulated Annealing (PSA) and genetic algorithms [32]. DE is a very effective combinatorial optimization method that has been applied in diverse automatic control areas [33], power systems [34], and power electronics [35]. The increasing use of the bio-inspired algorithms in control tuning is based on their individual population (possible solutions), and the convergence to a value closer to the optimal solution in the final generation [36].

Some of the DE applications in power systems are in topics such as voltage stability assesstment [37], automatic generation control (AGC) [38], induction generation [39], PSS tuning [34], [40], voltage power (source) converters [41], optimal power flow [42], electricity forecast [43], etc.

DE has been proposed as a control methodology for fuzzy logic tuning inference system parameters for nonlinear process control in [44]. The FADE algorithm adapts the fuzzy logic controller parameters while obtaining the information of the system to be controlled.

This innovative technique is applied in this paper for the improvement of the synthetic inertial control response of power systems under penetration of non-synchronous generation. The application of the DE looks for an adequate diminution of the Instantaneous Frequency Deviation (IFD or nadir) through the improvement of the fuzzy control parameters respecting the electrical and/or mechanical constraints. Moreover, since typical synthetic inertia approaches rely on user-experience tuning and, only a few approaches have shown the possibility of optimizing the active power injection [45], a further study is required and, therefore, is the motivation of this document.

The tuning of the Fuzzy Logic Controller (FLC) is developed based on an on-line co-simulation script-Simulink training system. Two test power systems are proposed in order to observe the frequency response under nonsynchronous generation inclusion. The first test system represents an aggregated power system and the ideal supplementary inertia control. The second test system, is the two-area system where one of the synchronous machines has been replaced by a full aggregated wind power system. Both test systems are completely developed for frequency 
studies in Simulink. The results show the IFD and frequency response improvement thought the controllers evolution process.

The paper is organized as follows: In Section 2, the research motivation regarding the frequency and inertial response is presented. Also, the definition of non-synchronous generation and its relation with the synthetic inertia are introduced. In Section 3, the theoretical fundamentals of the Fuzzy Adaptive Differential Evolution (FADE) control method are presented. Section 4 presents the architecture of the two test power systems and their modeling. Section 5 presents the simulation results considering the two control scenarios; the ideal one with minimal constraints, and the second one incorporating the full aggregated wind turbine. Finally, the conclusions and future work are given.

\section{Frequency Response}

The frequency control in a power system after a large disturbance is performed in different stages and time frames, namely inertia frequency, Frequency Containment Reserve (FCR) (primary control) and Frequency Restoration Reserves (FRR) (secondary control).

Inertial response is inherent in the system due to rotating mass of machines synchronously-connected providing counter response within seconds to oppose the frequency deviation following a loss of generation or a load event [46].

In a synchronous system, in the case of losing a generating unit, the frequency drops because of the imbalance between generation and load. The system frequency response is reflected in the power system instantaneously. During the first period, the inertial response of the spinning machines in the entire system, reacts by releasing or storing kinetic energy tending to reduce the frequency deviation. System inertia is defined as the total amount of kinetic energy stored in all rotating masses.

The inertial constant of an individual generator can be interpreted as the time that generator can provide full output power from its stored kinetic energy, taking values between 2 to 9 seconds.

Beyond the inertial response, the frequency is first stabilized and then restored to the nominal frequency by the FCR (governor action) and secondary controllers, respectively. The FCR acts as a proportional controller avoiding large frequency deviations; however, a steady state error still remains in the frequency response. The response of this control is given in seconds $(<30$ s). FRR returns the frequency back to its nominal value and also restores the reserves; its deployed time frame is given in minutes.

Figure 1 shows the dynamic response of the system frequency after disconnection of one generator. In the figure, the Maximum Instantaneous Frequency Deviation (IFD) (in cyan) and the post-disturbance Steady-State Frequency Deviation (SSFD) (in purple) are also indicated.

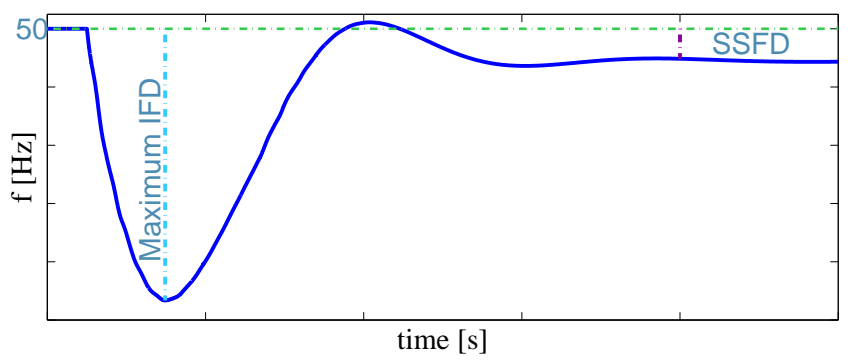

Figure 1: Frequency Response after a Frequency Event

\subsection{Non-synchronous Generation and Synthetic Inertia}

In this paper, non-synchronous generation is defined as when the power is supplied or absorbed through power electronic converters (DC-AC) to/from the grid system. For wind power turbines applications, Voltage Source Converters (VSC) have been employed to represent Full Rated Converters (FRC), Doubly-Fed Induction Generator (DFIG), and High Voltage Direct Current (HVDC) and Multi-terminal HVDC connection [11]. The non-synchronous generation allows controlling active and reactive power control. However, the power generation is completely decoupled from the system, and is consequently unable to contribute dynamically to the system [47, 48]. Thus, if the synthetic inertia control option is not added, the decoupling displaces synchronous machines [49]. 
The synthetic inertial response is an effective way to contribute to the system inertia. Different control proposals have been used to mimic the inertia; some of them add a derivative term of frequency in the droop control loops equations [50]. The widely used control scheme for the synthetic inertia control is shown in Figure 2. The derivative of the system frequency, $f_{\text {sys }}$, is obtained and the power reference is modified. To avoid the noise in the measurements, a low-pass filter is used together with the derivative function block.

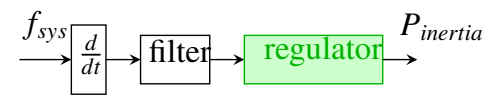

Figure 2: Synthetic Inertia Control Loop

The dynamics of the system frequency $f_{\text {sys }}$ are written as:

$$
2 \sum H\left(\frac{d f_{s y s}}{d t}\right)=P_{m, s y s}-P_{e, s y s}+P_{n s, s y s}
$$

where, $P_{m, s y s}$ is the equivalent prime mover in the system and $P_{e, s y s}$ is the equivalent generation output of the system. The inertial enhancement control from the non-synchronous generation $P_{n s}$ involved in the system is:

$$
P_{n s}=P_{\text {ord }}-\mathscr{F}_{s i} \frac{d f}{d t}
$$

where $\mathscr{F}_{s i}\left(\frac{d f_{s y s}}{d t}\right)$ is a synthetic inertia function control $P_{\text {inertia }}$ and, $P_{\text {ord }}$ is the ordinary power supplied by the non-synchronous generation. Hence, resulting in the following dynamics of the system frequency:

$$
2\left(H_{s y s}+\frac{\mathscr{F}_{s i}}{2}\right) \frac{d f_{\text {sys }}}{d t}=P_{m, s y s}-P_{e, s y s}+P_{\text {ord }}
$$

Thus, by integrating the inertial control loop, the overall system inertia can be improved.

\section{Differential Evolution Preliminaries and Algorithm}

\subsection{Fuzzy Logic Control}

Fuzzy logic is a means for transforming linguistic knowledge into a mathematical model; it transforms the human decision-making levels into numerical set-based control rules. It has been applied extensively to the field of automatic control where it succeeded in the modelling and control of many systems which are not easy to establish with the precise model. However, since the fuzzy controller is based on an expert's knowledge and experiences, there are some flaws. In the design process, the fuzzy control table and rules are fixed, not guaranteeing optimal control rules, and therefore not getting the desired control performance or effect [51]. The design of a Fuzzy Logic System (FLS), shown in Figure 3, includes the design of a Rule-base composed of if-then statements which controls an Inference Engine. Various input quantities can be fuzzified with the help of a Fuzzifier and fed to the Inference Engine. The logistic output of the inference Engine is defuzzified to generate a scaled Output quantity.

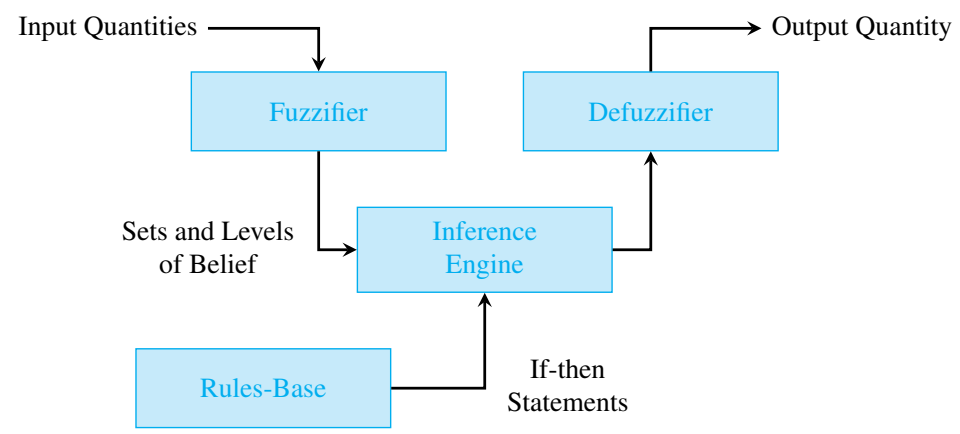

Figure 3: Fuzzy Logic Structure 


\subsection{Differential Evolution and Membership Function Adaptability}

The Differential Evolution (DE) algorithm is an evolutionary algorithm for global optimization over continuous domains introduced in [52]. The Fuzzy Adaptive Differential Evolution (FADE) algorithm, is a systematic evolutionary optimization algorithm which acts on the survival of the fittest, and has been designed for searching the membership functions with improved performance [44].

Evolutionary programming is used to evolve simultaneously the structure and the fuzzy parameters rule-base for a given task. The decisions are modelled with a fuzzy basis function expansion model [53]. The fuzzy membership function is a mixture of Gaussian functions which means that the variances and weights are tuned through DE algorithm, as illustrated in Figure 4. DE algorithm is chosen due to its advantages in performance and operation in optimisation problems compared to classical evolution algorithms [32],[54], and previous implementations on Voltage Source Converters (VSC) [55], and multi-agents problems [56]. Only a few studies have been reported that enhance the inertial response in power systems using FLC [57]-[59], and specially, only one uses an optimization technique [60]. Hence, the FADE application presented in this document brings the opportunity to emphasize, and observe the constraints involved along the control loops involved. The main characteristic of the DE algorithm is that the new generation is generated based on the parameters of the best individual and the difference in the chromosome of two random individuals.

In the performed study, the individuals are set to frequency and RoCoF. The goal is to achieve a minimum IFD. Since some rules may be uncertain, the weights of the rules are optimized too. The range of membership function parameters is determined based on the changes on the frequency response and its derivation (RoCoF). Figure 4 shows the representation of the synthetic inertia control loop in more detail. The blocks in blue, grey and green represent the measurements and the control signal that goes to the plant, the inertial power in this case, the synthetic inertia regulator and the fuzzy inference system.

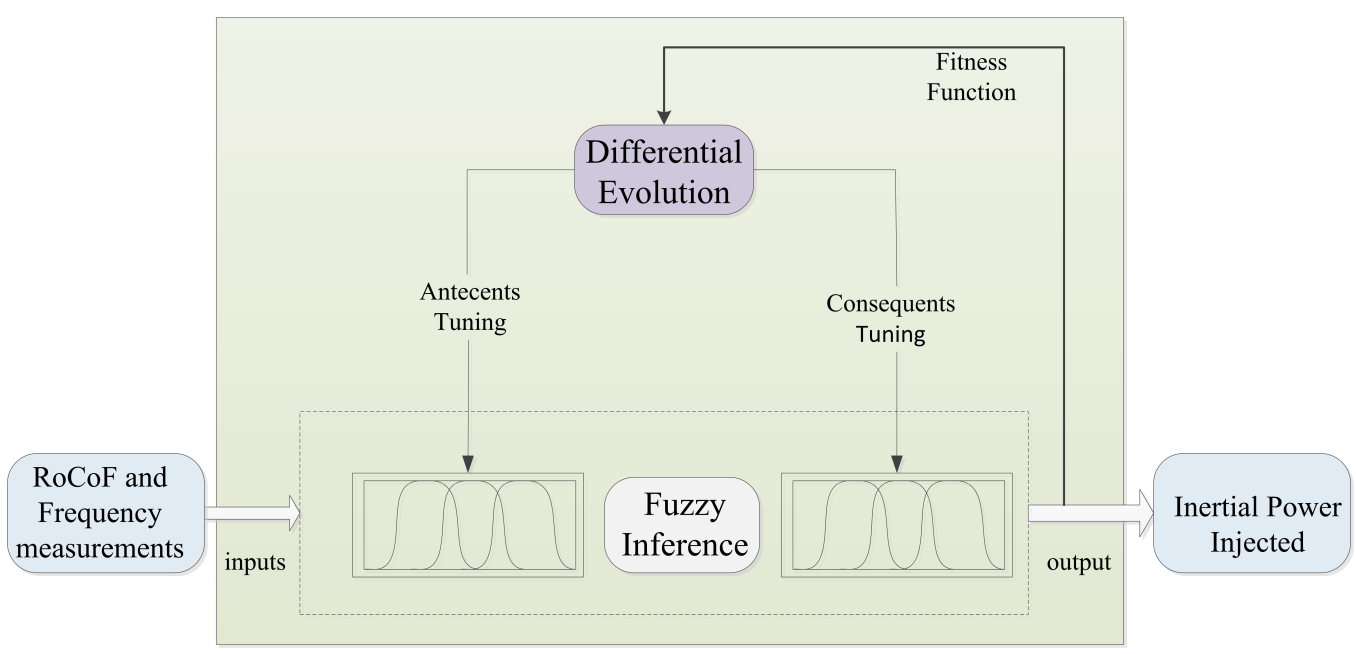

Figure 4: Synthetic Inertia Control based on Fuzzy Adaptive Differential Evolution Diagram

The final control values are the result of a Fuzzy Inference system defined in (1) with $N$ inputs, $M_{c}$ rules of the singleton type with a $T$-norm operator. The aforementioned system follows the characteristics described in Table 1 .

$$
f(x)=\frac{\sum_{l=1}^{M_{c}} y_{l}\left(\prod_{i=1}^{N} \mu_{A_{i}^{l}}\left(x_{i}\right)\right)}{\sum_{l=1}^{M_{c}}\left(\prod_{i=1}^{N} \mu_{A_{i}^{l}}\left(x_{i}\right)\right)}
$$

Gaussian membership functions $\mu(x)$ are considered for this case. These functions are expressed as:

$$
\mu_{A}(x, \sigma, c)=e^{\frac{-(x-c)^{2}}{2 \sigma^{2}}}
$$


where $c$ and $\sigma$ are the mean and the variance of the membership function, respectively.

\subsection{Differential Evolution Algorithm}

A DE algorithm begins by randomly generating $p n$-dimensional vectors. These vectors (called individuals) form a population that evolves over the course of the algorithm's run [61]. The steps of the DE algorithm are explained next and depicted in Figure 5:

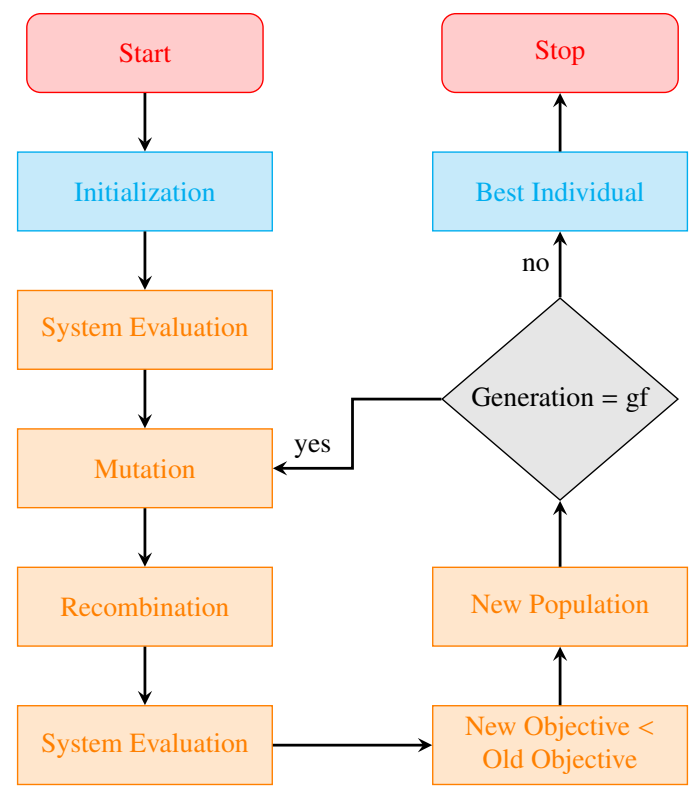

Figure 5: Differential Evolution Algorithm

\subsubsection{Chromosome}

The chromosome contains the characteristics of each individual. Each chromosome is divided into two parts: priority and action. And each part is further subdivided into three sections: means, deviations and centers. Means and deviations are equal in length to the product of the number of rules and the number of inputs. The center section is of equal length to the number of rules. The parameters of the chromosome are represented by real numbers which are randomly initialized between 0 and 1 , in order to cover the whole spectrum of solutions [43].

A chromosome represents each individual population in the evolution process. Each chromosome is assigned to a parameter position that represents the antecedent and consequent membership functions. It is defined $p_{a}$ as the number of parameters that characterize the membership functions shape (i.e. Gaussian), $n$ as the vector length of the fuzzy system and $M_{c}$ as the rules number.

For Multiple Inputs - Single Output (MISO), non-normalized fuzzy system with a complete rule base, the chromosome length $L_{v}$ is:

$$
L_{v}=M_{c} \cdot n \cdot p_{a}
$$

Note that, in this case, it is MISO control system because it takes two inputs: the frequency error and the frequency error derivative RoCoF.

\subsubsection{Population Structure}

The population structure consists of a population size $N_{p}$ of $D$ parameters with real values. The population $P$ has $x$ vectors given by:

$$
P_{x, g}=\left(X_{i, g}\right), i=0,1, \ldots, N_{p}-1, g=0,1, \ldots, g_{\max }
$$




$$
X_{i, g}=\left(x_{j, i, g}\right), j=0,1, \ldots, D-1
$$

The index $g=0,1, \ldots, g_{\max }$ points out the generation number where the vector belongs. Each vector is assigned a population index $i$, whose domain is from 0 to $N_{p}-1$. To the parameters in the vectors are assigned the index $j$, whose domain is from 0 to $N_{p}-1$. Once the population is initialized, DE mutates randomly choosing the vectors producing an intermediate population, $P_{v, g}$, of $N_{p}$ mutant vectors, $v_{i, g}$ :

$$
\begin{gathered}
P_{v, g}=\left(v_{i, g}\right), i=0,1, \ldots, N_{p}-1, g=0,1, \ldots, g_{\max } \\
V_{i, g}=X_{i, g}=\left(x_{j, i, g}\right), j=0,1, \ldots, D-1
\end{gathered}
$$

Each vector in the current population is recombined with a mutant to produce a test population $P_{u}$, of $N_{p}$ test vectors, $u_{i, g}$ :

$$
\begin{gathered}
P_{u, g}=\left(u_{i, g}\right), i=\left(v_{i, g}\right), i=0,1, \ldots N_{p}-1, g \\
u_{i, g}=\left(u_{i, g}\right), j=0,1, \ldots, D-1
\end{gathered}
$$

\subsubsection{Initialization}

Each population vector is initialized randomly. The initial value $\left(g_{0}\right)$ of the $j$-th parameter of the $i$-th vector is:

$$
x_{j, i, 0}=\operatorname{rand}_{j}(0,1)\left(b_{j, U}-b_{j, L}\right)+b_{j, L}
$$

The rand function returns a uniform distributed random number between the range $[0,1]$. In order to initialize the population vector, the vectors $b_{L}$ and $b_{U}$ define the lower (minimum) and upper (maximum) limits respectively.

\subsubsection{Mutation}

The DE algorithm performs a mutation, based on the distribution of the solutions in the current population [62]. The Mutation number is the relation that determines the probability that an individual has to start the mutation process in which its chromosome could change.

The mutation vector is generated from three individuals of the current generation: one of them is the best individual of the previous generation, and the other two are randomly selected. All selected individuals are different in order to propagate the characteristics of all vectors.

The DE algorithm then mutates and recombines the current population in order to produce a test population of $N_{p}$ individuals. In particular, the differential mutation adds a scaled vector sampled randomly to a third vector:

$$
v_{i, g}=x_{r 0, g}+F\left(x_{r 1, g}-x_{r 2, g}\right)
$$

The scale factor $F(0,1)$ is a positive real number which controls the population evolution rate. The base vector index $r 0$ is chosen randomly.

\subsubsection{Selection}

If the test vector $u$ has a value less or equal than the objective function vector, $x_{i, g}$, then it replaces the vector in the next generation. Otherwise, the vector keeps its place in the population for at least one more generation.

$$
x_{i, g+1}= \begin{cases}u_{i, g}, & \text { if } f\left(u_{i, g}\right) \leq f\left(x_{i, g}\right) \\ x_{i, g}, & \text { otherwise }\end{cases}
$$

Once the population has been created, its mutation, recombination and selection processes are repeated again until the particular termination criteria is satisfied. 


\subsubsection{Recombination}

The recombination is performed individual by individual, and is only possible if the fitness function of the mutated individual is better than the current individual.

\subsubsection{Termination Criteria}

The termination criteria adopted for DE is to stop the search process when the desired (pre-selected) number of generations is reached.

The target of the controller is to evaluate the dynamic response of the control system. In this case, the undershoot, the overshoot and the small stable steady-state error of the dynamic response are used as the evaluation criteria.

$$
f(\phi)=\omega_{1} t_{s}+\omega_{2} \sigma+\sum\left(\omega_{3} e^{2}+\omega_{4} u^{2}\right)
$$

where, $t_{s}$ represents the the start-up time, $\sigma$ is the overshoot/undershoot, $e$ indicates the error difference between the desired value and the actual value, $u$ indicates the output of the fuzzy controller, and $\omega_{1}, \omega_{2}, \omega_{3}$, and $\omega_{4}$ are constant coefficients. The goal here is to identify the values for the membership functions such that the best dynamic response is achieved, subject to, $\phi_{\text {lower }} \leq \phi \leq \phi_{\text {upper }}$ bounds.

Here $\phi$ is the controller structure, and $\phi_{\text {lower }}$ and $\phi_{\text {upper }}$ are the lower and upper bounds respectively of the membership functions.

\subsubsection{Differential Evolution Parameters}

The DE algorithm parameters are shown in Table 1. The initial population of the algorithm is created with a random uniform distribution probability. The number of individuals $N_{p}$ is established experimentally.

The optimization process has been fulfilled using DE. The algorithm parameters are shown in Table 1. As can be seen, the population size and generation number is 20 and 50 respectively.

Table 1: Differential Evolution Parameters

\begin{tabular}{|c|c|}
\hline Generation Number & 20 \\
\hline \hline Population Size $N_{p}$ & 50 \\
\hline Mutation Rate & 0.5 \\
\hline Cross Probability $C_{r}$ & 0.8 \\
\hline Codification & Real \\
\hline Target Function & RMSE \\
\hline
\end{tabular}

where RMSE stands for Root Mean Square Error. The scale factor $F_{s}$ varies according to the typical values. The cross probability $C_{r}$ is established as a value close to 1 (i.e, 0.8 ). Additionally, it uses the DE/best/1/bin variation due to it presents a better performance.

The FLC parameters are shown in Table 2.

Table 2: Differential Evolution Parameters

\begin{tabular}{|c|c|}
\hline Membership Functions & Gaussians \\
\hline \hline Inference & 50 \\
\hline Rules Number & 25 \\
\hline Class Number Rules & $35 \%$ \\
\hline Non-class Number Rules & $65 \%$ \\
\hline Defuzzifier & Centroid \\
\hline
\end{tabular}




\subsection{Co-simulation Environment}

The simulation is performed by combining Matlab-scripting and Matlab/Simulink environments. The FADE algorithm is programmed as a script which calls the the Simulink file at every iteration. The Simulink file contains the test power system, which has been designed completely with Simulink blocks (not Simpower), due to the needs of a frequency event. Figure 6 represents the co-simulation interface and design implementation of the FADE algorithm in the problem stated, the optimal IFD through synthetic inertia controller. Purple color represents the processes evaluated in the Matlab-script, and blue color block represents the Simulink control system evaluated.

Since the scripting and simulation are performed in an entirely compatible software, there is no need for an extra interface or processing. However, the computational effort is highly time-consuming.

The DE algorithm acts a controller which modifies the set of parameters of the $i$-th population, which consists of $p$ individual control systems. This cycle is repeated until the convergence criteria is met, and the operation is completed with the extraction of the best individual of the population. In the evaluation step of DE algorithm, a simulation is performed for each $C S_{i}$. The performance criteria are met if the system's response does not surpass an allowed area. The DE randomly generates an initial population process; the Simulink model transmits to the DE algorithm a fitness value, which is then used until the termination criteria is reached.

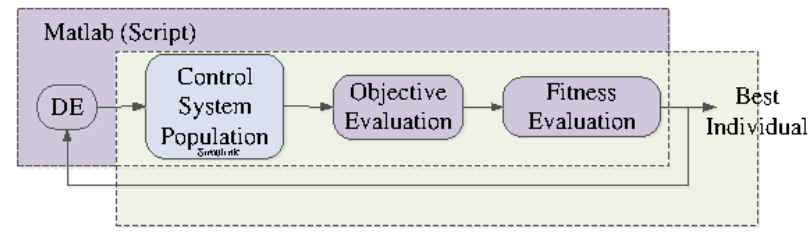

Figure 6: Co-Simulation Interface

\section{Test Power Systems Modelling}

\subsection{Aggregated Frequency Control System}

Based on the Center of Inertia (CoI) representation, the frequency of different areas can be described by a uniform area frequency. The system can be represented by a single generic unit, aggregating the turbines and the hydro speed governor models. This model is commonly used for power system studies. In this document, it is merely used for observing the action of the controller and understand the performance of the system on a higher level. The model is shown in Figure 7. Note the system has no losses (in the converter) and the synthetic inertia signal is taken directly from the speed/frequency deviation signal. Therefore, the control does not have any limitation regarding the power since the synthetic inertia control is acting directly in the system. However, it is restricted by the control tuning process. The synthetic inertia function $\mathscr{F}_{s i}$ has been added in the control loop as shown in Figure 7. 


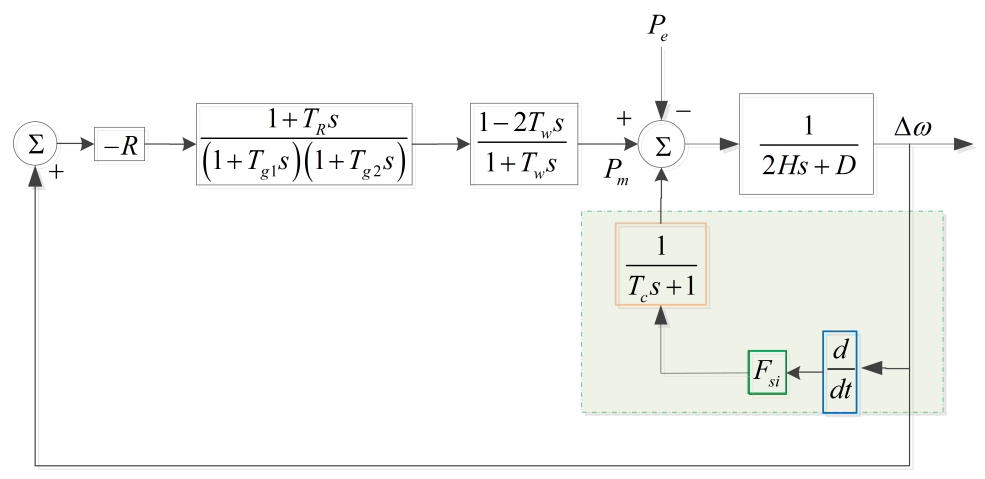

Figure 7: Transfer Function Model of an Aggregated Power System

The purpose of testing the FADE algorithm on this system, even though it can be considered a simplistic system, is to provide a comparative performance between the inherent inertia given by the system and the modeled synthetic inertia.

The data of the used power system is based on the aggregated model found in [63], and shown in Table 3. This represents the aggregated model of Sweden, Finland and Norway. In addition, some typical values for the turbine controller have been used.

Table 3: Aggregated System Parameters

\begin{tabular}{|c|c|}
\hline Parameter & Value \\
\hline \hline$T_{R}$ & 3.5 \\
\hline$T_{G}$ & 0.2 \\
\hline$T_{\omega}$ & 1.01 \\
\hline$M$ & 9.68 \\
\hline$D$ & 0.517 \\
\hline
\end{tabular}

\subsection{Two-Area Test System}

The single line diagram of the second test case system is shown in Figure 8. The test system consists of two fully symmetrical areas linked by two $230 \mathrm{kV}$ lines of $220 \mathrm{~km}$ length [68]. Each area is equipped with two identical round rotor generators rated at $20 \mathrm{kV} / 900 \mathrm{MVA}$. The nominal power system frequency for the test case model is $50 \mathrm{~Hz}$.

In this paper, for study purposes, one of the generators has been replaced by non-synchronous generation of an aggregated wind farm model at bus 1 .

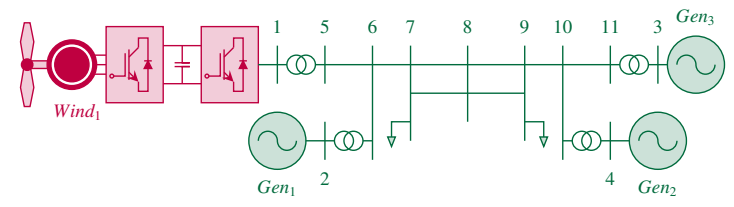

Figure 8: Two-area Test System Including non-synchronous Generation

\subsubsection{Wind Farm Aggregated Model}

The following equation is known to be a good representation of the mechanical power that can be extracted from the generator shaft of a wind turbine [69], [70]: 


$$
P_{t}=\frac{1}{2} \rho A v^{3} C_{p}(\lambda, \beta)
$$

where $\rho$ is the air density, $A$ is the area swept by the rotor blades, $v$ is the wind speed, $\beta$ denotes pitch angle, and $C_{p}$ is a function of the pitch angle of the turbine blade. The tip speed ratio $\lambda$ is defined as:

$$
\lambda=\frac{\omega_{t} R}{v}
$$

where $\omega_{t}$ and $R$ are the shaft speed and rotor radius respectively.

Figure 9 shows a simplified block diagram of the active power control of a WTG model. The inputs of this block are the incoming wind, the electrical power $P_{g}$ injected by the WTG, and the power set point $P_{\text {set }}$ which is dominated by the current control injection. Hence, controlling the $d$-axis current is the equivalent of controlling the power output and controlling the $q$-axis current corresponds either to voltage or reactive power.

The torque is controlled by a speed controller. The normal approach is to use the rotational speed of the turbine as an input signal. This signal provides a reference torque, and if the electric torque is larger than the mechanical torque the turbine will decelerate and the electric torque set point will decrease.

The mechanical speed regulation in the power limiting region is implemented by controlling the blade pitch angle $\beta$. The control signal $u_{\beta}$ is given by the following PID control scheme [67]:

$$
\begin{gathered}
u_{\beta}=-C_{p t}(s)\left(\omega_{r e f}-\omega_{m}\right) \\
C_{p t}(s)=K_{p p}\left(1+\frac{1}{T_{i} s}+\frac{T_{d} s}{1+\gamma T_{d} s}\right)
\end{gathered}
$$

where, $\omega_{r e f}$ is the reference for the regulation, and $K_{p p}, T_{i}, T_{d}$ and $\gamma$ denote control parameters.

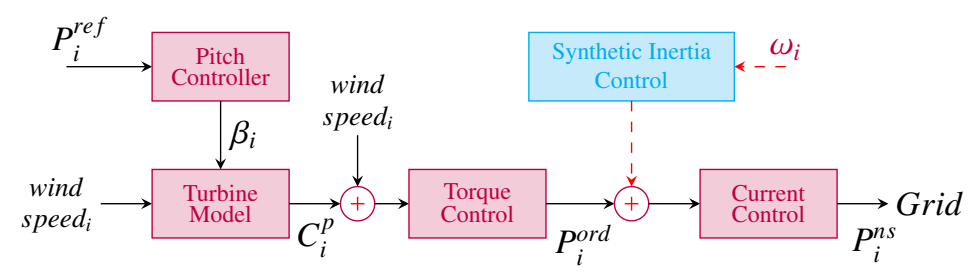

Figure 9: Active Power Wind Farm Schematic Diagram

The main purpose of the synthetic inertia controller $K_{s i}$ is to improve the steady-state frequency response. The active damping approach is applied to the current control and also to the synthetic inertia control loop.

\subsubsection{Current Control}

Most of the WTs are equipped with a power electronic converter in order to inject the power into the grid. The control of the grid connected converters relies on the current control [63]. Additionally, since the current control loop is the actuator, where the active power injection is modeled, it is necessary to be included in the complete plant model for the dynamic FADE simulation.

A basic structure of VSC-HVDC system is shown in Figure 10. A conventional back-to-back VSC system involves two VSC converters with identical configurations, connected via a DC link. In this study, the right-hand side converter, $V S C_{1}$ is controlling the active power injected into the AC grid and subjected to the extra power injection by the synthetic inertia supplementary control. For the inverter operation, there exist the following voltage equations in the form of $d-q$ synchronous frame. 


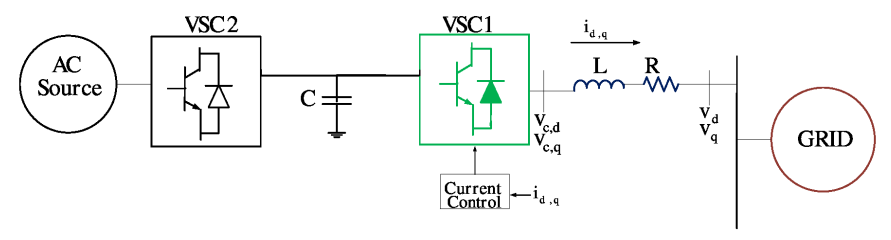

Figure 10: Full Rated Converter

The conventional $d-q$ current control has been widely studied in the literature [65],[66]. A synchronous $d-q$ reference approach is conventionally employed to facilitate VSC control. In this paper, the whole system is modeled in the $d-q$ frame. The dynamics of the $d-q$ axes are:

$$
\begin{aligned}
& R i_{d}+L \frac{d i_{d}}{d t}=v_{c, d}+\omega L i_{q}-v_{d} \\
& R i_{q}+L \frac{d i_{q}}{d t}=v_{c, q}-\omega L i_{d}-v_{q}
\end{aligned}
$$

The inverter decoupled voltage control of $i_{d}$ and $i_{q}$ is noted as follows:

$$
\begin{aligned}
& v_{d}=u_{c, d}-L \omega i_{q}+v_{d} \\
& v_{q}=u_{c, q}+L \omega i_{d}+v_{q}
\end{aligned}
$$

where, $u_{c, d}$ and $u_{c, q}$ are control signals of the $d$ and $q$ axes respectively.

The active power controller produces the $d$-axis current reference for the inner current controller according to the active power reference. In a similar way, the reactive power controller calculates the $q$-axis current reference from the voltage reference. The direct and quadrature axes are coupled via coupling terms $\omega L i_{d}$ and $\omega L i_{q} . R$ and $L$ stand for the equivalent combined resistance and inductance respectively of the phase reactor and transformer.

Figure 11shows the block diagram of the conventional $d-q$ control approach.

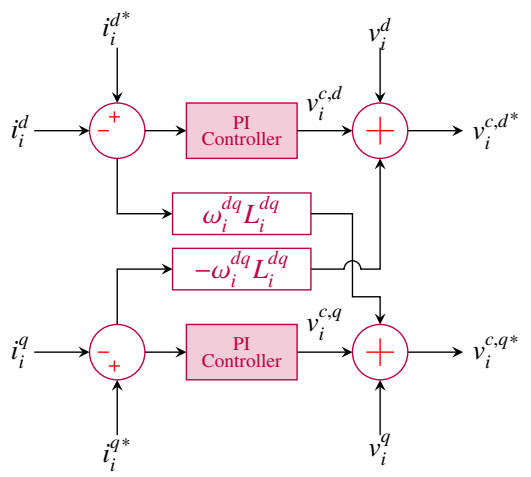

Figure 11: Current Control blocks

Note that the Pulsewidth Modulation (PWM) effect has been neglected in the converter.

Currents are translated to active and reactive power through:

$$
P=v_{d} i_{d}
$$

$$
Q=-v_{q} i_{q}
$$


Hence, by controlling the $d$ - axis current is the equivalent of controlling the power output. By controlling the $q$ - axis current either voltage or reactive power can be controlled. The only limitation of the reactive power capability is the current rating in the inverter compared to active current. As the current is decomposed the power deviation translates to a change in $d$-axis current, whereas the voltage deviation translates to a change in $q-$ axis current to change the reactive power output.

\section{Simulation Results and Discussion}

In order to evaluate the efficacy of the method on the reduction of the IFD and the improvement of the frequency response through the FADE, time-domain simulations have been performed on the two proposed test power systems.

\subsection{Aggregated System}

As mentioned earlier, the aggregated system does not have power restrictions for supplying the extra power coming from the synthetic control. The only restriction involved in FADE is the limitation of the controller parameters in order to not overcome the reference set-point. Without this restriction, some time response results could reach an over-frequency point, which means a complete power-consumption imbalance. Note that this application does not involve the secondary control (FRR), and therefore, the frequency set-point cannot/should not be reached.

The fuzzy membership sets $\mu(x)$ (five membership functions per input) evolution is shown in Figure 12. The FADE algorithm adjusts the function membership parameters while it is continuously checking the objective function. It uses Gaussian functions and the variation of their parameters conform the control parameters per generation. As can be seen in Gen 10, most of the means have mutated enough to be outside of the 0-1 region, this relative fast change is the result of high constant of mutation rate.
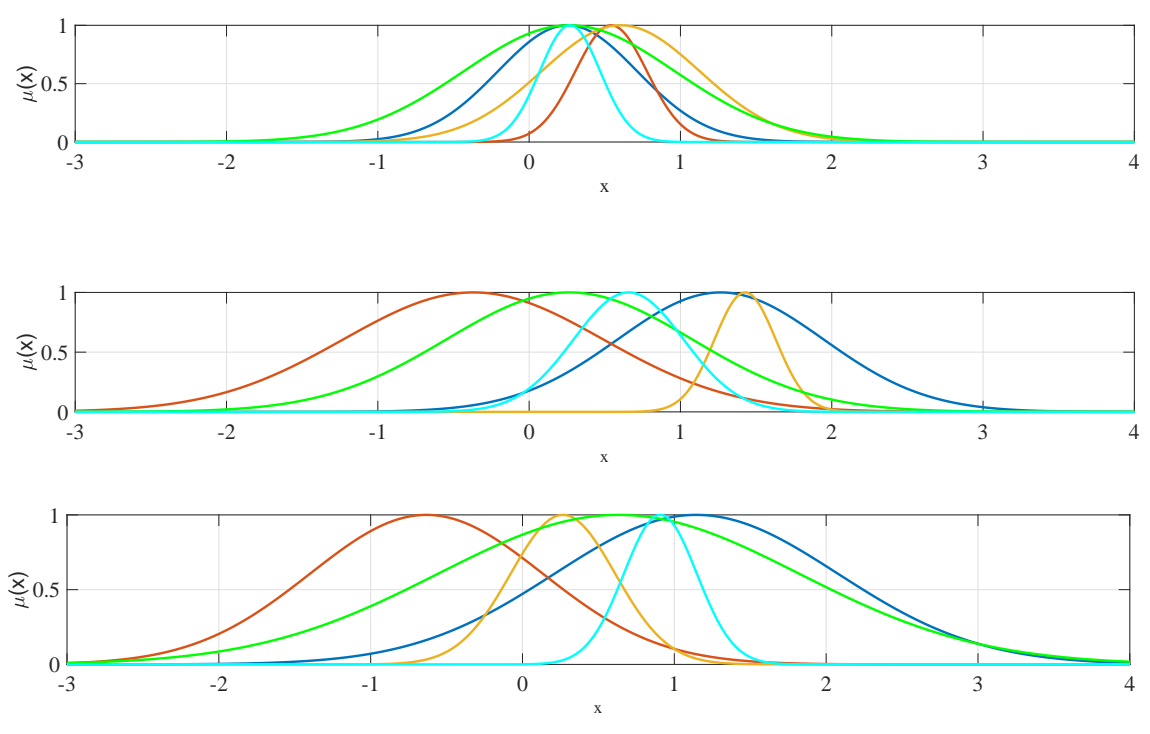

Figure 12: Best individual Fuzzy Membership Function Tuning Process for three generations

Figure 13 illustrate the convergence of the FADE algorithm. The performance index of the best parameters in each generation are shown. Due to the simplicity of the power system model, the control parameters obtained are close to the reference after three generations. This confirms the excellent convergence property of the FADE method. The performance is classified into worst (in blue), average (in orange) and best (in red) individual. The best individual (in red) is shown in a separate zoomed figure (Figure 13b) where it can be seen that since its first generation, the response $(50.0004 \mathrm{~Hz})$ is quite close to the reference of $50 \mathrm{~Hz}$. 


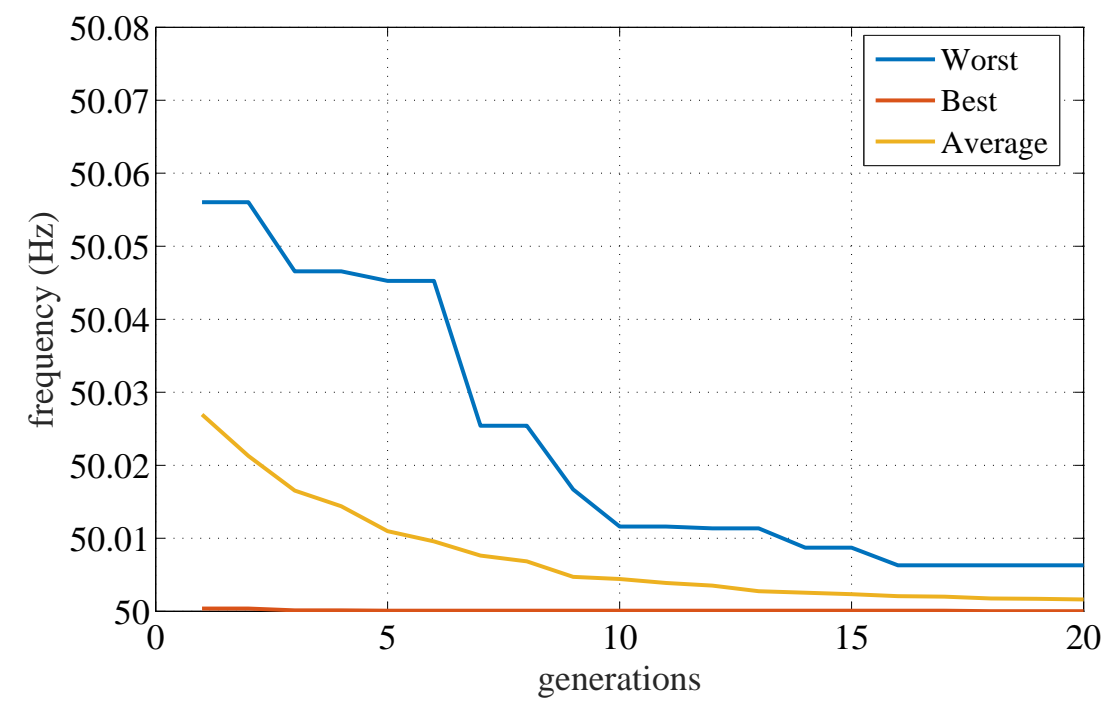

(a) Learning Process

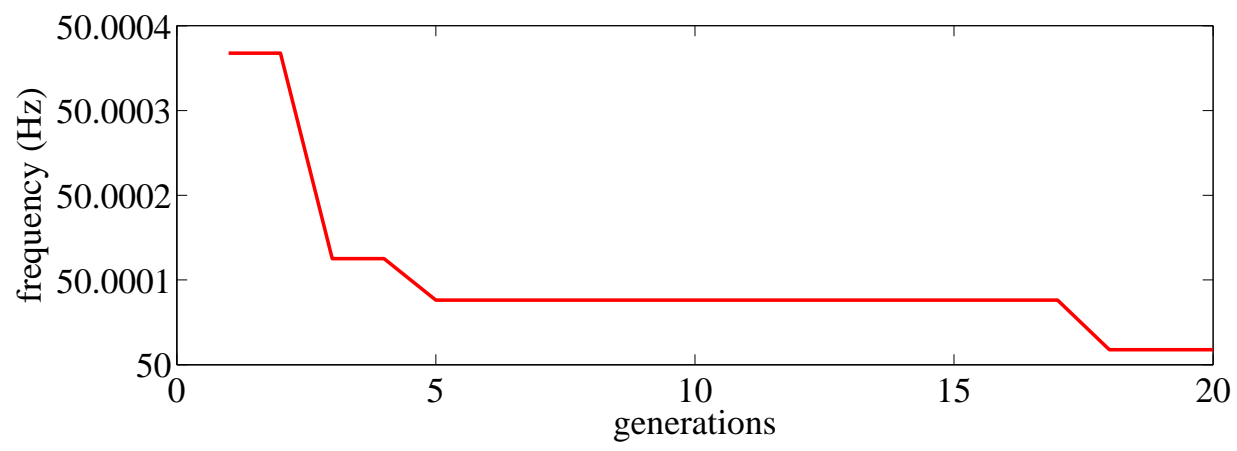

(b) Zoom: Learning Convergence

Figure 13: Learning Process of the Best, Average and Worst Individuals

The proposed controller, based on the training process and the continuous observation of the system (simulation by simulation), looks to obtain the appropriate fuzzy logic parameters to maintain the system near the reference. In the first stage, the system starts with the highest IFD based on the load disturbance; this is presented in time response in blue (Gen1) in the Figure 14. After the test, all the individuals of the first generation the DE algorithm look for the best individual of the current generation (Gen1) to transmit a part of its genetic information to the next generation and so on (Gen5-Gen18) till the stop criteria is reached.

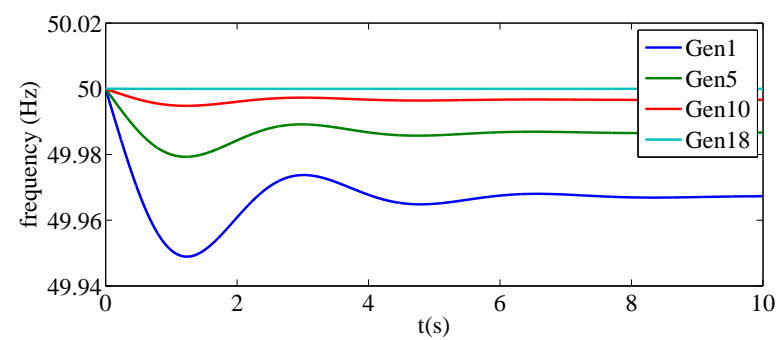

Figure 14: System response for the best individuals of selected generations 


\subsection{Two-Area System}

Following the same process, the two-area system including the wind farm model and the synthetic inertia control is studied next.

The learning process for the two-area system for the worst, average and best individual convergences is shown in Figure 15a and 15b (zoomed version). All of the learning process converge close to the reference in the Gen7, but only the the best individual (in red) gets closer to the reference with an error of 1.5 approx. It is noteworthy that the system should retain a minimum error in order to not force the controllers to an unstable point and the load disturbance has not been removed, and the AGC is not included.

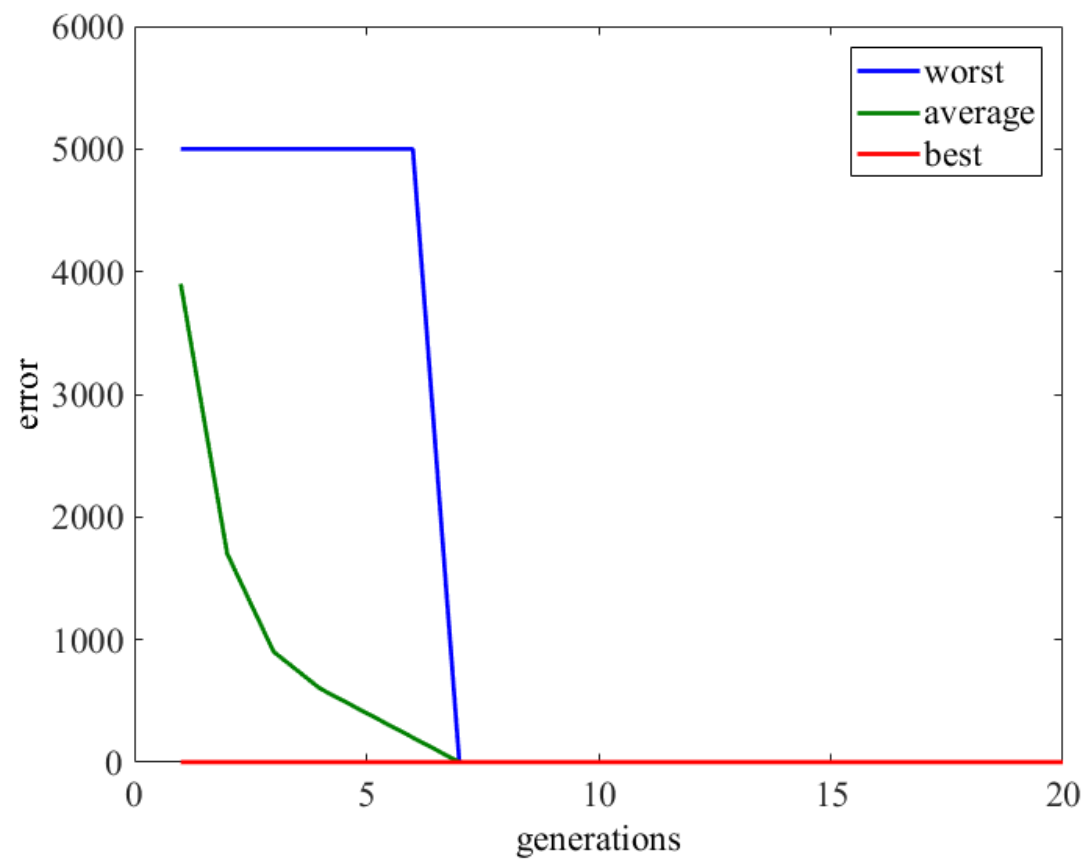

(a) Learning Process

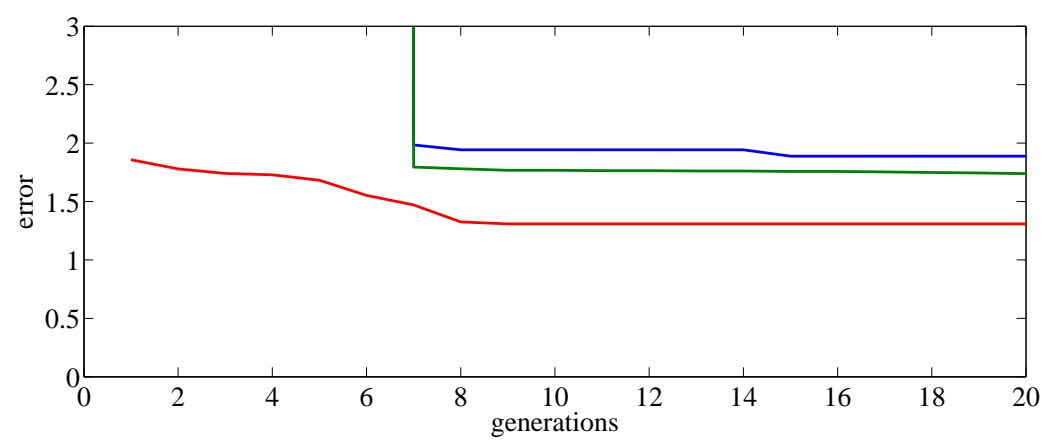

(b) Zoom: Learning Convergence

Figure 15: Learning Process of the Best, Average and Worst Individuals

Based on the above, only the best individuals are studied further; the responses with the worst and average individual performance are discarded. The frequency measured in the system is given by the COI (Center of Inertia). The time response evolution of the frequency is shown in the Figure 16a. Some relevant observation can be seen from the figure. The system starts with a large IFD, and then Gen 1 to Gen 6 reduce significantly the IFD. However, the action 
has an overshoot (undershoot) after the primary control is involved. This overshoot is reduced in generations Gen 10 and Gen 12 .

The most suitable time responses are obtained in Gen 14 and Gen 15 where clearly the IFD has been decreased as expected. However, for these two generations, both IFDs are relatively close. These solutions could be the implemented ones for the operator in charge; nevertheless, protection limits and grid code compliance should be carefully checked according to each country/region.

Furthermore, even though the Gen20 shows the most significant reduction in the IFD, it presents an oscillatory behavior after reaching convergence. Therefore, it cannot be the best solution for the power system and it will involve a mechanical/power electronics higher effort or simply the malfunction of the wind farm. Note that normally wind farms operate under the headroom operation, and even with the best synthetic controller the wind farm cannot deliver that extra-power.

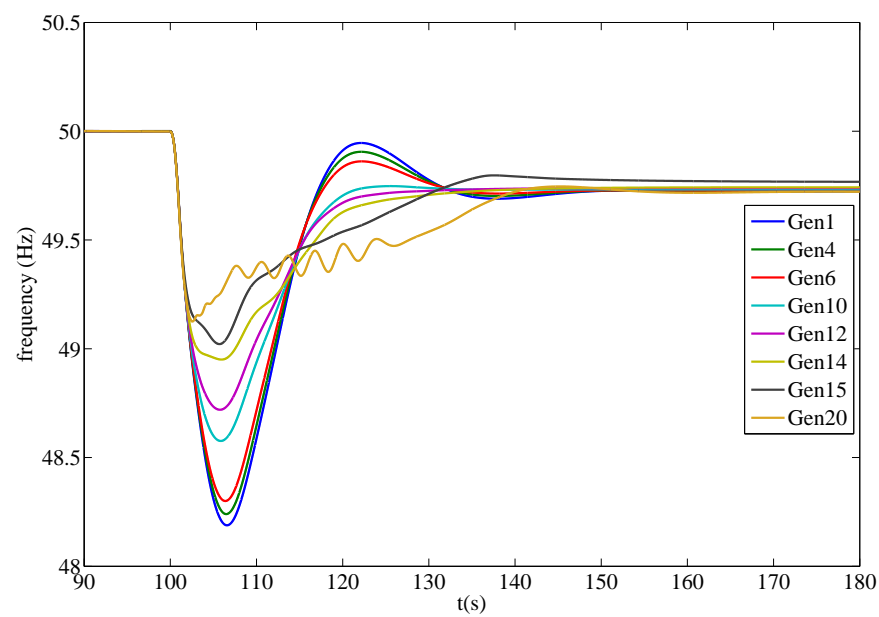

(a) System Response for the Best Individuals of Selected Generations

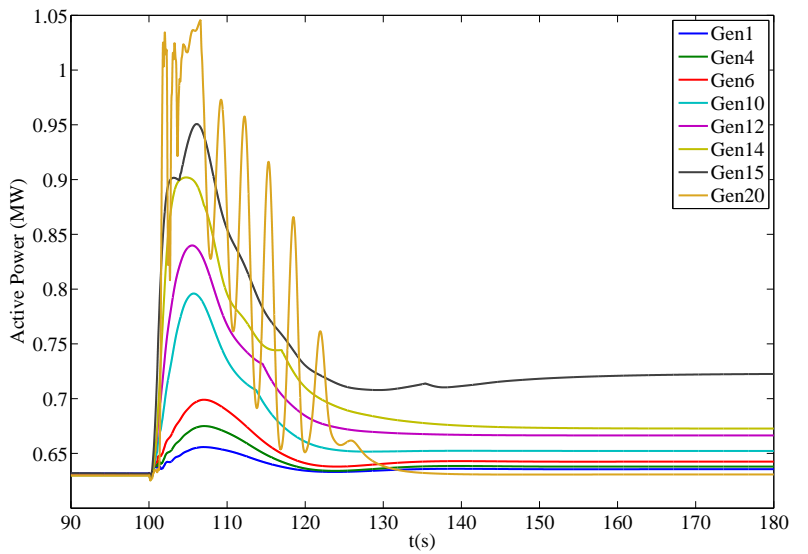

(b) Wind Farm Power Response for the Best Individuals of Selected Generations

Figure 16: Two-Area System Time-Response

The power injected though the converter with the synthetic inertia control is shown in Figure 16b. Figure presents the power increased response given by the FADE generational process. Note that even though the other frequency controllers (e.g. the governors) in the system are operating, they are rated at fixed nominal power and their optimization is not the scope of this document. The figure confirms the oscillatory behavior of the power produced by the individual controller obtained in Gen20. The best controller solutions for this case and the test system can be the generations Gen 14 or Gen 15 .

Table 4 presents the FADE generation process and the IFD obtained.

Table 4: IFD vs Generation

\begin{tabular}{|c|c|}
\hline Generation & IFD [Hz] \\
\hline \hline 1 & 48.19 \\
\hline 4 & 48.24 \\
\hline 6 & 48.30 \\
\hline 10 & 48.58 \\
\hline 12 & 48.72 \\
\hline 14 & 48.95 \\
\hline 15 & 49.03 \\
\hline 20 & 49.12 \\
\hline
\end{tabular}


In order to verify the control capability, an increase in the wind speed reference is proposed. Previous results were obtained with $13 \mathrm{~m} / \mathrm{s}$. Therefore, the wind power set-point is changed to $16 \mathrm{~m} / \mathrm{s}$. Gen 15 optimal control results are used for the simulation with the new wind speed reference in order to show that can be used for another change in the system.

Figure 17 shows that the synthetic inertia control based-FADE under the two mentioned speeds. IFD parameter is reduced as expected, though the power injection increased with a larger value of speed. The inertia released coincides with the the drop in the wind generator rotor speed and the variation of the pitch angle function. Note that wind turbine is operated having a headroom in order to provide the extra power injection required.
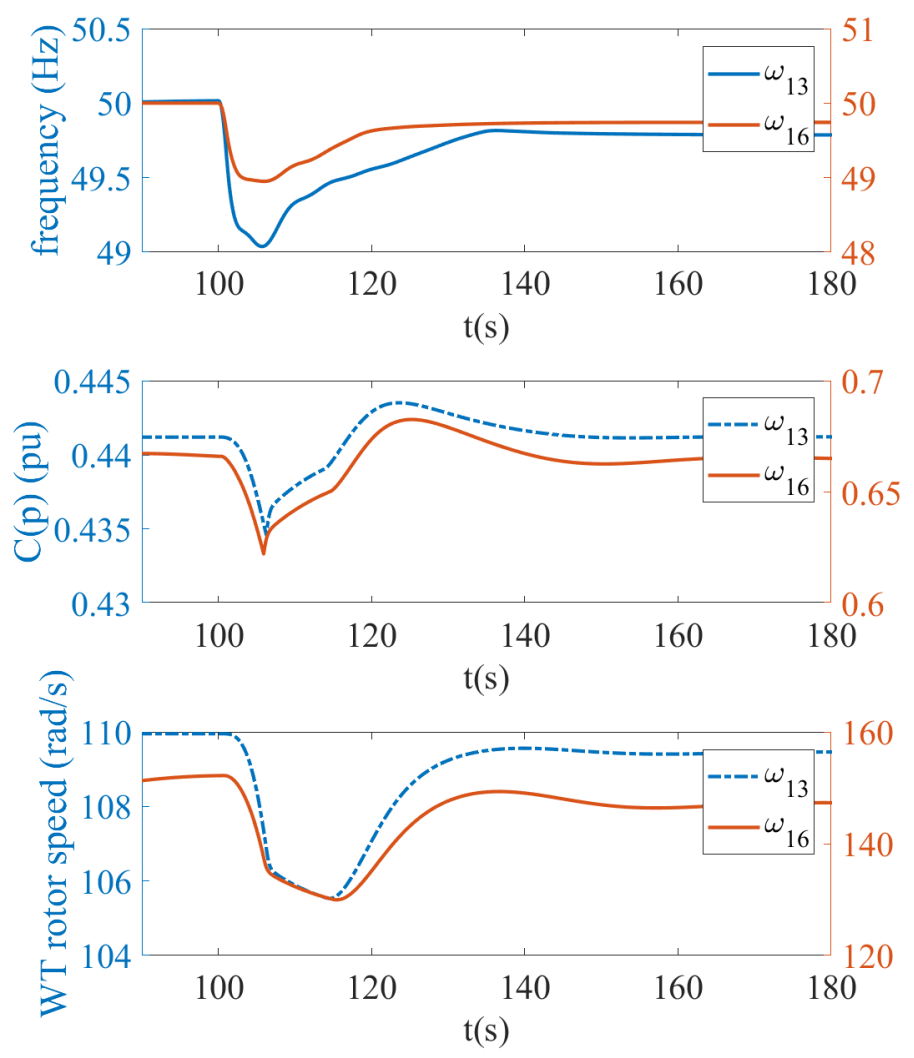

Figure 17: Frequency Response with speed variation

Next, a comparison of both FADE and traditional synthetic inertia control methods is presented. The latter follows the structure shown in Figure 2. Gen 15 is used for comparison purposes. Figure 18 shows the time response obtained. Note that the gain of the traditional synthetic control has also been optimized. However, since FADE method uses two membership inputs as explained above, it has a significant IFD improvement. The results show that the minimum frequency swing is reduced from 48.75 to $49 \mathrm{~Hz}$ approx. Also, the maximum steady state result is reached faster at about $138 \mathrm{~s}$ instead of $150 \mathrm{~s}$. Finally, the steady state error is reduced. 


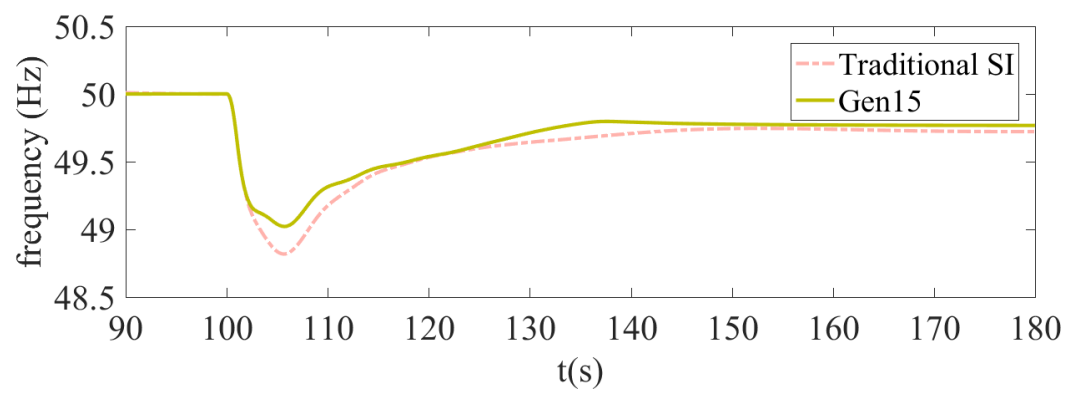

Figure 18: Best individual Fuzzy Membership Function Tuning Process

\section{Conclusions and Future Work}

In this paper, a fuzzy adaptable logic controller based on DE algorithm has been developed for the synthetic inertia control in power systems. It has been shown that it is possible to reach a desirable reduction in the IFD based on the improvement of the control parameters, therefore improving the frequency response under a drastic load event.

Two systems were studied. The first one was built for the mere purpose of observing how the system reacts with the controller. The synthetic inertia controller, in this case, takes the frequency and the RoCoF measurements, and through the controller injects an extra power for the inertia improvement. However, it does not have any restriction (ideal case) of power; thus, it obtains a perfect tracking of the control and frequency response, which is of course not realistic. In the case of the second system, the synthetic inertia control is tested on a common transmission system where one of the synchronous machines has been replaced by a wind farm, whose model includes the mechanic dynamics and the full converter model. In this case, the tuning process reach different time responses and definitely improves the frequency response. Nevertheless, it is shown that there are some limits for the power injection that even can make the system oscillate, which is undesirable in practical systems. The responsibility of the expert/designer for the FADE controller will be to decide what is the best solution according to the system.

This method can be applied to large power systems. However, it requires a detail model of the whole system and a robust platform for its computation/execution and the running of the training on-line system. But otherwise, automates the system expert time for tuning the controller, which it can be useful for realistic power systems applications.

Differential Evolution enables obtaining a better fuzzy parameters configuration and to have an specific fuzzy set for each application during the evolution process and the results can be viewed.

The design of control systems by using FADE algorithm helps the designer improve the system and also, to give a clearer vision of the system behaviour.

The fitness function evaluates the time frequency response and encloses the IFD time frame; however, other functions can be applied as well for future works.

FADE method has been compared to the traditional synthetic inertia method. The main advantage of FADE's synthetic controller is the use of two membership inputs for tuning purposes. Moreover, the obtained optimal solution has shown to able to be deal with changes different from the original training set, and guarantee the IFD minimization respecting the electrical and mechanical limits.

Future work will be focused on comparing/combining recent optimization methods, and application to larger transmission power systems in HiL systems.

\section{References}

[1] M. Fischer, S. Engelken, N. Mihov, and A. Mendonca, "Operational experiences with inertial response provided by type 4 wind turbines", IET Renewable Power Generation, vol. 10, no. 1, pp. 17-24, 2016.

[2] P. Tielens and D. Van Hertem, "The relevance of inertia in power systems", Renewable and Sustainable Energy Reviews, vol. 55, pp. 999-1009, Mar. 2016.

[3] J. Conto, "Grid challenges on high penetration levels of wind power", in 2012 IEEE Power and Energy Society General Meeting, 2012, pp. $1-3$.

[4] E. Spahic, D. Varma, G. Beck, G. Kuhn, and V. Hild, "Impact of reduced system inertia on stable power system operation and an overview of possible solutions", in 2016 IEEE Power and Energy Society General Meeting (PESGM), Jul. 2016, pp. 1-5. 
[5] J. Aho, P. Fleming, and L. Y. Pao, "Active power control of wind turbines for ancillary services: A comparison of pitch and torque control methodologies", in 2016 American Control Conference (ACC), Jul. 2016, pp. 1407-1412.

[6] M. J. Till, Y. Liu, Y. Liu, M. Patel, and T. King, "Frequency response of the Eastern Interconnection due to increased wind generation", in 2014 IEEE PES General Meeting — Conference Exposition, Jul. 2014, pp. 1-5.

[7] F. Teng and G. Strbac, "Evaluation of Synthetic Inertia Provision from Wind Plants", in 2015 IEEE Power Energy Society General Meeting, Jul. 2015, pp. 1-5.

[8] W. Litzenberger, K. Mitsch, and M. Bhuiyan, "When It's Time to Upgrade: HVdc and FACTS Renovation in the Western Power System", IEEE Power and Energy Magazine, vol. 14, no. 2, pp. 32-41, Mar. 2016.

[9] T. Knuppel, J. N. Nielsen, K. Jensen, A. Dixon, and J.Ostergaard, "Small-signal stability of wind power system with full-load converter interfaced wind turbines", IET Renewable Power Generation, vol. 6, no. 2, pp. 79-91, 2012.

[10] J. Conroy and R. Watson, "Aggregate modelling of wind farms containing full-converter wind turbine generators with permanent magnet synchronous machines: transient stability studies", IET Renewable Power Generation, vol. 3, no. 1, pp. 39-52, Mar. 2009.

[11] H. R. Chamorro, C. A. Ordonez, J. C. Peng, and M. Ghandhari, "Non-synchronous generation impact on power systems coherency", Transmission Distribution IET Generation, vol. 10, no. 10, pp. 2443-2453, 2016.

[12] F. Wilches-Bernal, J. Chow, and J. Sanchez-Gasca, "A Fundamental Study of Applying Wind Turbines for Power System Frequency Control", IEEE Transactions on Power Systems, vol. PP, no. 99, pp. 1-10, 2015.

[13] N. W. Miller, "Keeping It Together: Transient Stability in a World of Wind and Solar Generation", IEEE Power and Energy Magazine, vol. 13, no. 6, pp. 31-39, Nov. 2015.

[14] P. Kundur, Power System Stability and Control, McGraw-Hill. New York, 1994.

[15] T. Kovaltchouk, V. Debusschere, S. Bacha, M. Fiacchini, and M. Alamir, "Assessment of the impact of frequency containment control and synthetic inertia on intermittent energies generators integration", in 2016 Eleventh International Conference on Ecological Vehicles and Renewable Energies (EVER), Apr. 2016, pp. 1-8.

[16] F. M. Gonzalez-Longatt, "Effects of the synthetic inertia from wind power on the total system inertia: simulation study", in 2012 2nd International Symposium on Environment Friendly Energies and Applications (EFEA), Jun. 2012, pp. 389-395.

[17] X. Zhu, Y. Wang, L. Xu, X. Zhang, and H. Li, "Virtual inertia control of DFIG-based wind turbines for dynamic grid frequency support", in IET Conference on Renewable Power Generation (RPG 2011), Sep. 2011, pp. 1-6.

[18] F. Gonzalez-Longatt, "Activation schemes of synthetic inertia controller on full converter wind turbine (type 4)", in 2015 IEEE Power Energy Society General Meeting, Jul. 2015, pp. 1-5.

[19] L.-R. Chang-Chien and Y.-C. Yin, "Strategies for Operating Wind Power in a Similar Manner of Conventional Power Plant", IEEE Transactions on Energy Conversion, vol. 24, no. 4, pp. 926-934, Dec. 2009.

[20] N. Ullah, T. Thiringer, and D. Karlsson, "Temporary Primary Frequency Control Support by Variable Speed Wind Turbines - Potential and Applications", IEEE Transactions on Power Systems, vol. 23, no. 2, pp. 601-612, May 2008.

[21] J. Aho, A. Buckspan, J. Laks, P. Fleming, Y. Jeong, F. Dunne, M. Churchfield, L. Pao, and K. Johnson, "A tutorial of wind turbine control for supporting grid frequency through active power control", in American Control Conference (ACC), 2012, 2012, pp. 3120-3131.

[22] A. Zilouchian and M. Jamshidi, Intelligent control systems using soft computing methodologies, English. Boca Raton, FL: CRC Press, 2001, OCLC: 45708127.

[23] Computing with Words, English. S.1.: Springer-Verlag Berlin and Heidelberg GmbH Co. KG, 2012.

[24] N. L. Diaz, T. Dragicevic, J. C. Vasquez, and J. M. Guerrero, "Fuzzy-logic-based gain-scheduling control for state-of-charge balance of distributed energy storage systems for DC microgrids", in 2014 IEEE Applied Power Electronics Conference and Exposition - APEC 2014, Mar. 2014, pp. 2171-2176.

[25] V. S. Vakula and K. R. Sudha, "Design of differential evolution algorithm-based robust fuzzy logic power system stabiliser using minimum rule base", Transmission Distribution IET Generation, vol. 6, no. 2, pp. 121-132, Feb. 2012.

[26] S. M. Muyeen, R. Takahashi, and J. Tamura, "Operation and Control of HVDC-Connected Offshore Wind Farm", IEEE Transactions on Sustainable Energy, vol. 1, no. 1, pp. 30-37, Apr. 2010.

[27] H. F. Wang, H. Li, and H. Chen, "Coordinated secondary voltage control to eliminate voltage violations in power system contingencies", IEEE Transactions on Power Systems, vol. 18, no. 2, pp. 588-595, May 2003.

[28] J. L. Mayorga, C. Dominguez-Bonilla, A. Gutierrez, F. Jimenez, and H. Chamorro, "Development of real-time control emulator in FPGA using HiLeS methodology”, in IECON 2015 - 41st Annual Conference of the IEEE Industrial Electronics Society, Nov. 2015, pp. 004 076-004 081.

[29] D. Llano, M. Tatlow, and R. McMahon, "Control algorithms for permanent magnet generators evaluated on a wind turbine emulator test-rig", in 7th IET International Conference on Power Electronics, Machines and Drives (PEMD 2014), Apr. 2014, pp. 1-7.

[30] L. Meng, A. Luna, E. R. Díaz, B. Sun, T. Dragicevic, M. Savaghebi, J. C. Vasquez, J. M. Guerrero, M. Graells, and F. Andrade, "Flexible System Integration and Advanced Hierarchical Control Architectures in the Microgrid Research Laboratory of Aalborg University", IEEE Transactions on Industry Applications, vol. 52, no. 2, pp. 1736-1749, Mar. 2016.

[31] L. Vanfretti, M. Chenine, M. S. Almas, R. Leelaruji, L. Ängquist, and L. Nordström, "SmarTS Lab - A laboratory for developing applications for WAMPAC Systems", in 2012 IEEE Power and Energy Society General Meeting, Jul. 2012, pp. 1-8.

[32] K. V. Price, R. M. Storn, and J. A. Lampinen, Differential evolution: a practical approach to global optimization, English. Berlin; New York: Springer, 2005, OCLC: 262677779.

[33] M. Leon, M. Evestedt, and N. Xiong, "Application of Adaptive Differential Evolution for model identification in Furnace Optimized Control System", in 2015 7th International Joint Conference on Computational Intelligence (IJCCI), vol. 1, Nov. 2015 , pp. 48-54.

[34] T. Mulumba and K. A. Folly, "Application of Self-Adaptive Differential Evolution to tuning PSS parameters", in 2012 IEEE Power Engineering Society Conference and Exposition in Africa (PowerAfrica), Jul. 2012, pp. 1-5.

[35] O. Tezak, D. Dolinar, and M. Milanovic, "Snubber design approach for dc-dc converter based on differential evolution method", in The 8th IEEE International Workshop on Advanced Motion Control, 2004. AMC '04, Mar. 2004, pp. 87-91.

[36] Y. Zhang, Y. j Gong, H. Zhang, T. L. Gu, and J. Zhang, “Towards Fast Niching Evolutionary Algorithms: A Locality Sensitive Hashing-Based 
Approach", IEEE Transactions on Evolutionary Computation, vol. PP, no. 99, pp. 1-1, 2016.

[37] Y. Xu, Z. Y. Dong, F. Luo, R. Zhang, and K. P. Wong, "Parallel-differential evolution approach for optimal eventdriven load shedding against voltage collapse in power systems", Transmission Distribution IET Generation, vol. 8, no. 4, pp. 651-660, Apr. 2014.

[38] B. K. Sahu, S. Pati, and S. Panda, "Hybrid differential evolution particle swarm optimisation optimised fuzzy proportional integral derivative controller for automatic generation control of interconnected power system", Transmission Distribution IET Generation, vol. 8, no. 11, pp. 1789-1800, 2014

[39] F. J. Lin, K. H. Tan, and C. H. Tsai, "Improved differential evolution-based Elman neural network controller for squirrel cage induction generator system", IET Renewable Power Generation, vol. 10, no. 7, pp. 988-1001, 2016.

[40] Z. Sun, N. Wang, D. Srinivasan, and Y. Bi, "Optimal tunning of type-2 fuzzy logic power system stabilizer based on differential evolution algorithm”, International Journal of Electrical Power Energy Systems, vol. 62, pp. 19-28, Nov. 2014.

[41] I. Riaño, "Sequential Learning Function applied to the design and tuning of a Fuzzy Controller for VSC", in Innovative Smart Grid Technologies Latin America (ISGT LATAM), 2015 IEEE PES, Oct. 2015, pp. 104-106.

[42] A. M. Shaheen, R. A. El-Sehiemy, and S. M. Farrag, "Solving multi-objective optimal power flow problem via forced initialised differential evolution algorithm", Transmission Distribution IET Generation, vol. 10, no. 7, pp. 1634-1647, 2016.

[43] I. Riaño and O. E. Perdomo, "Electricity price forecasting using a fuzzy system tuned with a Differential Evolution algorithm", in Innovative Smart Grid Technologies Latin America (ISGT LATAM), 2015 IEEE PES, Oct. 2015, pp. 792-795.

[44] J. Liu and J. Lampinen, “A Fuzzy Adaptive Differential Evolution Algorithm”, en, Soft Computing, vol. 9, no. 6, pp. 448-462, Jun. 2004.

[45] B. K. Poolla, S. Bolognani and F. Dörfler, ’Placing Rotational Inertia in Power Grids," 2016 American Control Conference (ACC), Boston, MA, 2016, pp. 2314-2320.

[46] P. Kundur, N. J. Balu, and M. G. Lauby, Power system stability and control, English. New York [etc.: McGraw-Hill, 2009 , OCLC: 781152137.

[47] G. Lalor, A. Mullane, and M. O’Malley, "Frequency control and wind turbine technologies", IEEE Transactions on Power Systems, vol. 20, no. 4, pp. $1905-1913$, Nov. 2005

[48] Y. Wang, G. Delille, H. Bayem, X. Guillaud, and B. Francois, "High wind power penetration in isolated power systems - assessment of wind inertial and primary frequency responses", IEEE Transactions on Power Systems, vol. 28, no. 3, pp. 2412-2420, 2013.

[49] D. Banham-Hall, C. Smith, G. Taylor, and M. Irving, "Investigating the limits to inertial emulation with large-scale wind turbines with direct-drive permanent magnet generators", in UKACC International Conference on Control 2010, Sep. 2010, pp. 1-6.

[50] Z. Miao, L. Fan, D. Osborn, and S. Yuvarajan, "Wind Farms With HVdc Delivery in Inertial Response and Primary Frequency Control", IEEE Transactions on Energy Conversion, vol. 25, no. 4, pp. 1171-1178, Dec. 2010.

[51] L. Shuai and S. Wei, "Optimization of fuzzy control rules based on differential evolution algorithm", in Guidance, Navigation and Control Conference (CGNCC), 2014 IEEE Chinese, Aug. 2014, pp. 2610-2613.

[52] R. Storn and K. Price, Differential evolution-a simple and efficient adaptive scheme for global optimization over continuous spaces. ICSI Berkeley, 1995, vol. 3.

[53] T. K. Yin and C. S. G. Lee, "Fuzzy model-reference adaptive control", in , Proceedings of the 33rd IEEE Conference on Decision and Control, 1994, vol. 4, Dec. 1994, 4130-4135 vol.4. 12

[54] U. K. Chakraborty, Advances in differential evolution, English. Berlin: Springer Verlag, 2008, OCLC: 288565559.

[55] Z. Salam and N. Bahari, "Selective harmonics elimination PWM (SHEPWM) using Differential Evolution approach", in 2010 Joint International Conference on Power Electronics, Drives and Energy Systems (PEDES) 2010 Power India, Dec. 2010, pp. 1-5.

[56] Y. Zheng, X. Xu, S. Chen, and W. Wang, "Distributed agent based cooperative differential evolution: A master-slave model", in 2012 IEEE 2nd International Conference on Cloud Computing and Intelligence Systems, vol. 01, Oct. 2012, pp. 376-380.

[57] K. Mentesidi, R. Garde, M. Aguado and E. Rikos, "Implementation of a fuzzy logic controller for virtual inertia emulation," 2015 International Symposium on Smart Electric Distribution Systems and Technologies (EDST), Vienna, 2015, pp. 606-611.

[58] M. Ramírez, R. Castellanos and J. G. Calderón, ’Fuzzy logic approach for inertial and frequency response from converter based wind power units," 2017 19th International Conference on Intelligent System Application to Power Systems (ISAP), San Antonio, TX, 2017, pp. 1-5.

[59] L. B. F. Leite, H. Siguerdidjane, H. D. Mathur and Y. K. Bhateshvar, "Wind power inertial support for inter-area oscillations suppression with fuzzy controller in varying load conditions," 2013 International Conference on Clean Electrical Power (ICCEP), Alghero, 2013 , pp. 751-754.

[60] R. Azizipanah-Abarghooee, M. Malekpour, M. Zare and V. Terzija, "A new inertia emulator and fuzzy-based LFC to support inertial and governor responses using Jaya algorithm,” 2016 IEEE Power and Energy Society General Meeting (PESGM), Boston, MA, 2016 , pp. 1-5.

[61] L. Skanderova, T. Fabian, and I. Zelinka, "Differential Evolution Enhanced by the Closeness Centrality: Initial Study", in 2015 International Conference on Intelligent Networking and Collaborative Systems, Sep. 2015, pp. 346-353.

[62] E. Mezura-Montes, J. Velázquez-Reyes, and C. A. Coello Coello, "A Comparative Study of Differential Evolution Variants for Global Optimization”, in Proceedings of the 8th Annual Conference on Genetic and Evolutionary Computation, ser. GECCO '06, New York, NY, USA: ACM, 2006, pp. 485-492.

[63] L. Saarinen, P. Norrlund, U. Lundin, E. Agneholm, and A. Westberg, "Full-scale test and modelling of the frequency control dynamics of the Nordic power system", in 2016 IEEE Power and Energy Society General Meeting (PESGM), Jul. 2016, pp. 1-5.

[64] M. Klein, G. Rogers, and P. Kundur, "A fundamental study of inter-area oscillations in power systems", IEEE Transactions on Power Systems, vol. 6, no. 3, pp. 914-921, Aug. 1991.

[65] J. V. d. Vyver, J. D. M. D. Kooning, B. Meersman, L. Vandevelde, and T. L. Vandoorn, "Droop Control as an Alternative Inertial Response Strategy for the Synthetic Inertia on Wind Turbines", IEEE Transactions on Power Systems, vol. 31, no. 2, pp. 1129-1138, Mar. 2016.

[66] F. Hafiz and A. Abdennour, "An adaptive neuro-fuzzy inertia controller for variable-speed wind turbines", Renewable Energy, vol. 92, pp. 136-146, Jul. 2016.

[67] N. Horiuchi and T. Kawahito, "Torque and power limitations of variable speed wind turbines using pitch control and generator power control", in Power Engineering Society Summer Meeting, 2001, vol. 1, Jul. 2001, 638-643 vol.1.

[68] J. Dannehl, F. W. Fuchs, S. Hansen, and P. B. Thogersen, "Investigation of active damping approaches for PI-based current control of gridconnected PWM converters with LCL filters", in 2009 IEEE Energy Conversion Congress and Exposition, Sep. 2009, pp. $2998-3005$.

[69] M. P. Kazmierkowski and L. Malesani, "Current control techniques for three-phase voltage-source PWM converters: a survey", IEEE Tran- 
sactions on Industrial Electronics, vol. 45, no. 5, pp. 691-703, Oct. 1998.

[70] B. Bahrani, S. Kenzelmann, and A. Rufer, "Multivariable- PI-Based Current Control of Voltage Source Converters With Superior Axis Decoupling Capability”, IEEE Transactions on Industrial Electronics, vol. 58, no. 7, pp. 3016-3026, Jul. 2011. 